\title{
APORTES A LA REFLEXIÓN METODOLÓGICA DEL TRABAJO SOCIAL CON LA INFANCIA VULNERABLE DESDE LA DOCTRINA DE PROTECCIÓN INTEGRAL: DE LA FORMACIÓN ACADÉMICA AL EJERCICIO PROFESIONAL EN CHILE
}

\section{Margarita Rojas Lambertini' Pablo Suárez Manrique ${ }^{2}$}

\section{Resumen}

La presente reflexión pretende entregar y aportar a la reflexión metodológica de aquellas personas, técnicos y profesionales que han optado por la defensa de los Derechos de los niños y niñas en los espacios científico-disciplinarios y técnico-profesionales, respetando y resguardando los principios de la dignidad infantil transversalmente en su quehacer, reconociéndoles en todo momento su integralidad de derechos en todos los espacios sociales como sujetos plenos.

Este trabajo es fruto de la doble mirada de los autores. Por una parte, las diversas asesorías metodológicas a profesionales y estudiantes que eligieron desarrollar investigaciones en y con la "infancia" en sus áreas críticas, donde el niño o niña fue considerado actor fundamental, y la otra, fruto de la vivencia profesional directa'en los diversos programas gubernamentales que atiende a la infancia vulnerable y donde se han registrado cambios progresivos en áreas claves de la acción profesional en Chile. [Descriptores: niña o niño actor, infancia vulnerable, derechos del niño].

\section{Abstract}

The present cogitation aims to contribute methodical reflection to people, technicians and professionals who had opted for the defense of the rights of the children on scientific-

${ }^{1}$ Trabajadora social del Servicio Nacional de Menores, Chile.

${ }^{2}$ Docente, Universidad Tecnológica Metropolitana, Santiago de Chile. 
disciplinary and vocational-technical spaces, respecting and safeguarding the principles of childhood dignity crosswise in their do, acknowledging at all times their rights integrity in all the social spaces as full subjects.

This study is the result of the double gaze of their authors, on one hand by the diverse methodical consultancies to professional and students who has chosen to carry out research on and with the "childhood" in their critical areas, where boys or girls were considered key players and on the other hand, is the result of the direct professional experience on the various government programs which serves to the vulnerable children and where progressive changes have been registered in key areas of professional action in Chile. [Keywords: girl or boy actor, vulnerable children, children's rights].

\section{De la doctrina del menor en situación irregular a la de protección integral}

La forma de tratar a los niños en los tiempos contemporáneos ha tenido un desarrollo que va desde el no de tener un claro concepto de la infancia, hasta el respeto de los derechos del niño como un ser humano que es. En el siglo XVIII eran tratados como cualquier adulto, se constituían en una carga o un apoyo para una familia dependiendo del estrato social al cual perteneciera, si cometían delitos eran recluidos junto a los adultos. Las primeras acciones hacia la Infancia que surgen son la creación de los orfanatos, para aquellos niños que eran abandonados por madres solteras o familias con muchos hijos.

El Estado empieza a preocuparse por los niños y jóvenes a fines del siglo XIX, y se centró en aquellos que infringían la ley. De ahí que crea las cárceles para los delincuentes juveniles. En el 1923, en Francia, se proclamaron los Derechos de los Niños, lo que provoca la preocupación por las circunstancias en que se encuentra esta población. Se establecen lugares especiales para prevenir la delincuencia infantil, siendo estos sitios en donde se internaban a los niños que vagaban, que sufrían de abandono o de negligencia por parte de sus padres.

Mediante un sistema legal, desde los años de 1930 a los años 1970 se aplica la llamada Doctrina del Menor Irregular donde se le llama "menor" a los niños y jóvenes por su calidad jurídica de menores de edad; situación que los hace incapaces ante la ley, donde se califican, tanto las inhabilidades físicas y 
morales de los padres como de los niños, dándole la categoría de padres que no cubren las necesidades morales y materiales de los niños y a estos últimos, se los considera abandonados o desprotegidos. Se crean los juzgados de menores y las casas de menores, creando así una judicatura especializada en el tema. Las facultades de estos jueces eran: 1) La corrección de menores que transgreden las leyes; 2) La protección de menores que requieren tutela jurídica o material; y 3 ) El enjuiciamiento de mayores que cometieran delitos en perjuicio de menores

Aquí nace la figura jurídica del discernimiento, en la cual a los jóvenes de 16 años, hasta la mayoría de edad (18 o 21 años según correspondiera) el juez determinaba su capacidad de comprender el delito cometido y según esta percepción, lo sometía a una medida de protección o al encarcelamiento como cualquier adulto. En Chile, en el 1967, con la dictación de la Ley $\mathrm{N}^{\circ} 16.618$, conocida como la Ley de Menores, se creó además la Policía de Menores, como un área de Carabineros de Chile. Esta rama podía detener a cualquier niño o joven de acuerdo a su estimación de la situación de riesgo social en que se encontraba, con el fin de ponerlo a disposición del Juez de Menores. En esta doctrina, se percibe a los niños como personas que no saben; que no tienen derecho a opinión, ni defensa; personas que deben ser cuidadas y protegidas; personas que reciben atención sin poder cuestionarla, por ser incapaces tanto ante la ley como ante la sociedad. De ahí que, estas dos instituciones sociales deben protegerlo y velar por él. Y esto, además por la presunción que ser pobre lo lleva a ser un potencial delincuente juvenil, al cual si no se le brindan todos los cuidados necesarios lo será. Por otra parte, se considera a la familia pobre como no protectora y ni cuidadora, por lo que se la desautoriza legalmente.

Desde esta visión del joven no se le aplican penas frente a la comisión de delitos, sino que son medidas de protección que ejerce el Juez de Menores en virtud de la potestad que le da la sociedad, donde discrecionalmente por su juicio u opinión puede decidir respecto de la situación del niño. Así, puede recluirlo por el tiempo que estime necesario, sin derecho a defensa en relación a descubrir si el joven cometió el delito o no, constituyéndose por esto en una medida tutelar que la sociedad ejerce sobre los niños y jóvenes. En esta concepción, el niño es objeto de derecho, no sujeto de derecho, donde otros 
emiten decisiones legales por él sin tener derecho a opinión, ni a defensa, donde no existe límite en las medidas de protección que se toman "a favor" del niño o joven.

Esta forma de percibir a los niños comenzó a entrar en crisis en la década de los años de 1980. Por una parte, debido a la gran cantidad de agresiones que sufrieron los niños de la calle en Brasil, donde estos niños empezaron a alzar su voz y a exigir sus derechos, y de otra, por los procesos de democratización que vivieron los países de Latinoamérica. Proceso que terminó con la aprobación de la Convención Internacional sobre los Derechos del Niño en 1989, suscrita por 57 países, y cuyo preámbulo señala:

...como antecedente es conveniente señalar que esta Convención fue adoptada por la Asamblea General de las Naciones Unidas el 20 de noviembre de 1989, preservando el espíritu de la Declaración de los Derechos del Niño de 1950, e incluye problemas e intereses contemporáneos que han surgido en los últimos treinta años, tales como la protección ambiental, el consumo de drogas y la explotación sexual. La Convención entró en vigor en 1990, después de ser ratificada por veinte países. Para el 1 de febrero de 1996 ha sido ratificada por 187 gobiernos de un total de 193.

Esta declaración obliga a los gobiernos que la suscriben a "adoptar todas las medidas administrativas, legislativas y de otra índole para dar efectividad a los derechos reconocidos en la presente Convención" (Convención de los Derechos de los Niños).

La denominada "Doctrina de Protección Integral de Derechos", se desarrolla a base a la Convención de los Derechos del Niño, por lo que el problema de niños, niñas y adolescentes, cambia de foco. Ya no lo constituye la necesidad, la carencia, sino la vulneración de sus derechos, siendo importante resguardarles las condiciones básicas para todos los seres humanos, como: la identidad, crecer en familia, protección contra la arbitrariedad, libertad de opinión, de asociación, de información, protección contra toda forma de perjuicio o de abuso físico o mental, de descuido o trato negligente, de malos tratos o explotación, derecho a la protección del niño mental o físicamente impedido para disfrutar de una vida plena y 
digna, asegurar a todos los niños el más alto nivel de salud, beneficiarlo con la seguridad social, garantizarle la igualdad de oportunidades ante la educación, cuidar por su derecho al descanso y el esparcimiento, a la vida cultural y a las artes, resguardar el derecho de todo niño ( o joven) que ha infringido las leyes penales, a la defensa y a aprender a respetar los derechos humanos y las libertades fundamentales de terceros, asegurándole su reintegración social.

Esta Doctrina no distingue entre niños y jóvenes pobres y no pobres, son todos iguales ante los derechos. No existen jueces especiales, sino que aquellos que ven las circunstancias que son atendibles a todas las familias. Estos jueces deben tomar decisiones asegurando estos derechos, por lo que existen atribuciones especiales en la judicatura que separan a los niños de sus familias, como última circunstancia frente a una gran trasgresión de sus derechos desde la misma familia, donde el Estado debe suplir su función en forma temporal y de la manera más apegada a la Convención. La privación de libertad sólo se usa para aquellos jóvenes que se ha comprobado que han cometido un delito, luego de un debido proceso (derecho a defensa), pero luego el Estado debe procurar la reinserción social del joven y el aprendizaje de que ellos deben responsabilizarse por sus actos.

Hoy en día, por ejemplo, la aplicación de la Convención, al igual que la Doctrina de Protección Integral, se han hecho difícil en Chile. Si bien se han dictado diferentes leyes que van acercando la mirada hacia el respeto de los derechos de los niños, aún queda mucho camino por recorrer para su absoluta aplicación. Esto, porque siendo Chile un país adultocentrista, todavía existe la concepción de que los adultos tienen siempre la razón, que los niños y jóvenes no tienen una visión formada de la realidad, por lo cual ellos deben ser protegidos por los adultos, , y por ende, en donde el niño o joven no tiene legitimado su derecho a opinión, a participación y a defensa. Esto implica que nos encontramos en un periodo de transición entre las dos Doctrinas (desde la irregularidad social a la protección integral).

\section{La doctrina de protección integral en una experiencia de formación de profesionales de Trabajo Social en educación superior}

Desde sus primeras manifestaciones de vida, el niño o niña siempre se ha constituido en preocupación de 
los trabajadores y trabajadoras sociales, incluso cuando la madre aún tiene plena autonomía sobre la vida que se gesta en su vientre. El niño o niña ha estado presente en toda la historia de la profesión incluso desde sus "protoformas", ya que el "nacimiento" constituye uno de los hechos sociales más importantes en la vida de una familia y uno de los hechos trascendentes para las naciones. Sin embargo, en nuestra sociedad, la niñez ha suscitado una preocupación retórica más que política, lo que se traduce en una abundante reflexión sobre el tema, pero escasos planes y proyectos de acción. Esta situación se traduce igualmente en el mundo del Trabajo Social y las universidades del país que imparten la carrera, donde el tema ha evolucionado desde el paradigma de la "minoridad en riesgo social" a "el niño y niña sujeto pleno de derechos", igualmente las escuelas pueden demostrar una producción de estudios sobre infancia, pero limitada al pregrado, desde donde es necesario e imprescindible avanzar.

En una primera etapa, los profesionales se guiaron por diversas teorías que, señalan por ejemplo: que la familia era para el niño o niña de 5 a 6 años, el principal agente socializador. Se concebía que en ese proceso se internalizaban las pautas de comportamiento y las habilidades sociales, y se vislumbraba que era en los juegos con su grupo de pares donde se comenzaba a adquirir un rol fundamental para autovisualizarse, desde la singularidad a la colectividad, donde la familia mantenía una hegemonía como fundamental agente socializador. La influencia de Piaget en esta materia fue considerable y determinante. En su obra se establece que la niñez se constituye en la etapa de la vida que da inicio al pensamiento racional, donde se despliega la reflexión y la observación para escudriñar los acontecimientos y así explicarlos, comprenderlos e interpretarlos desde una perspectiva lógica, logrando reconstruir la realidad, la noción de tiempo y espacio. Allí se reconoce la capacidad del niño de interactuar, imitar conductas, realizar juegos simbólicos, que de alguna forma podian dar luces de su realidad cotidiana, lo que podía interpretarse como primer esbozo de su opinión.

En ese paradigma, la niñez era igualmente el espacio significativo para el desarrollo humano donde se formaba el juicio moral. Para Piaget (2000) eran tres las dimensiones para la construcción moral: la justicia, la cooperación y la intencionalidad-realismo, donde la noción de cooperación era 
fundamental para el desarrollo intelectual del niño. El juicio moral del niño o niña se iniciaba con juicios rígidos y egoístas, pero en la medida que crece y se incorporaba al sistema educativo, comenzaba a desarrollar juicios flexibles con los cuales progresivamente iba determinando un código éticomoral que se incorporaba al lenguaje de ellos. Otro estudioso de la conducta infantil fue Erikson (2000), quien al igual que Piaget, consideraba que los niños o niñas se desarrollaban psicoevolutivamente a través de un proceso ordenado. Sin embargo, centró sus estudios en el proceso de socialización y la identidad personal, La cual se comienza a manifestar a través de sus comportamientos y su voz.

En la primera etapa de la reflexión académica, los niños y niñas fueron res-guardados y protegidos como seres con limitaciones objetivas de carácter psicobiológicas. Estas restricciones eventualmente operaron en el ámbito de la investigación generándose una categoría sociológica de infancia mediatizada y controlada a través de la voz y/o la observación científica de las personas adultas. De esta manera, el niño o niña adquirió una condición de objeto de estudio. Bajo estos preceptos, la niñez terminaría por tanto, cuando estas personas logran superar sus limitaciones naturales y logran adquirir una serie de habilidades y condiciones objetivas que le permiten alcanzar una identidad social básica que les otorga el derecho de situarse con éxito en una estructura de relaciones sociales asignadas, superando así, el primer estadio de desarrollo.

Esta categoría de infancia, se estableció desde mediados del siglo $X X$ consolidando una imagen de niñez que perdió su multiplicidad de sentidos y su riqueza metafórica; dejando que el Trabajo Social develara al niño o niña sólo como un registro de cualidades observables. Este tipo de paradigma incomodó a muchos profesionales prácticos que, al tratar de exponer sus trabajos con cierto rigor científico, encontraron que solo era legítimo el relato metodológico que establecía principios racionales, inmutables y universales para la generación de conocimiento. . Esta visión paradigmática, presentaba como principio de fiabilidad científica, en las propuestas de Campbell y Stanley (1978), que establecían la mínima imprescindible, que debían tener los procesos de investigación para demostrar consistencia y validación. Dichas circunstancias indispensables debían ser vigiladas 
por el investigador(a) para dar plena credibilidad y soporte a los procesos que generaban conocimiento. Entre estos se destacaba el factor maduración, referido a los procesos internos que viven las personas participantes en el momento que se desarrolla el proceso investigativo y que pudieran distorsionar el estudio, tales como edad, hambre, cansancio, etc. Es decir, disponer de aquel factor, entregaría la calidad confiable a la fuente de información. Desde esta perspectiva, podríamos suponer que procesos investigativos experimentales en niñas y niños, su juicio quedaría cuestionado en sí mismo por no disponer de la maduración necesaria para tolerar espacios destinados a generar conocimientos.

En este criterio, profesionales de Trabajo Social encontraron que la condición de niño o niña no era suficiente para desarrollar estudios, dado los cambios psicobiológicos y las fluctuación y variabilidad del lenguaje que presentan Desde allí, su condición se transformaba en un riesgo objetivo que podría generar una contaminación de las variables e inestabilidad de los mismos. Por otra parte, adoptarlos como sujetos de investigación significaba desarrollar extensos procesos de investigación y muestras voluminosas para garantizar la estabilidad en el registro y la predicción de la conducta futura (Barlow \& Hersen, 1988, establecimiento de tendencias y patrón de variación cíclica).

Otro tanto sucedía y sucede con ciertas posturas de la psicología clínica y forense en donde nos señalaban que, sólo ciertos niños reunirían requisitos para comunicar experiencias como verdaderas, instaurando así, una lógica protectora, pero excluyente, ya que visualiza y representa psicosocialmente al niño o niña como in-hábil, in-capaz, in-maduros e in-defensos, entre otros. Con ello se planteó que los niños (as) requerían exigencias mínimas para significar sus experiencias a partir del lenguaje y de la expresión gráfica como los dibujos de Karen Machover y Buck (figura humana, test del árbol, test de la familia). De esta manera, bajo este argumento general al niño o niña se le cuestiona en el fondo el derecho a la expresión y a su plena opinión. Por muchos años, profesionales del Trabajo Social en la práctica sintieron que las posturas científicas positivistas no representaban integralmente la realidad de su acción. Como lo señala Matus (1999), los paradigmas que reivindicaron la voz de los sujetos, permitieron y facilitaron su 
interés por la generación de aquel conocimiento que afloraba en su acción con niños y niñas.

La instauración progresiva de las metodologías cualitativas significaron en una primera etapa, que se instauran esbozos de trabajo científico que transitan, entre el niño(a) como ser biológico y como ser con capacidad de lenguaje y comportamientos sociales propios, apareciendo una categoría de infancia que conectó el proteccionismo a los mensajes y experiencias directas de los niños o niñas. Bajo este paradigma aparece el niño y niña como proyección de un discurso consciente desde donde se cuestiona o sustenta su escenario vivencial, mediado por la voz del experto cualitativo. La niñez aparece como tópicos de lenguaje, estilos lexicológicos o retoricas, en la que el actor o actriz no avanza para explicarse así mismo el porqué de la producción de sus expresiones, es decir hablan y son escuchados generando un avance significativo al ser considerado sujeto.

Esta experiencia se fortaleció con la Declaración Universal de los Derechos de los Niños y Niñas y la aparición de la Doctrina de Protección Integral. Además, permitió su expresión con plena libertad, manteniendo sin embargo, una determinada posición y una calidad de sujeto activo según sea su capacidad de habla. Ante esta situación re-aparecen y se consolidan los modelos participativos de investigación que fueron profusamente trabajados en tiempos de dictadura, y que al igual que antes, buscaron la actoria plena, pero ahora del niño y niña sin restricción.

Este paradigma acogió la presencia de una categoría de infancia autónoma y diversa que buscaba no solo la legitimidad del discurso presente, sino interpelaba a un espacio conversacional de consenso construyendo representaciones de la niñez desde sí mismo, lo que favorecería la instalación de prácticas innovadoras y la recomposición de la representación no solo colectivas sino también del propio niño o niña. Esta postura para profesionales de trabajo social implica esfuerzo, congruencia, consistencia y autocritica, ya que desplegar acciones de investigación de esta naturaleza implica una postura ética de re-conocimiento integral que no podemos ignorar, ya que, siempre existirá el peligro latente de establecer una nueva forma manifiesta de conocimiento-dominación, en la que personas mayores nuevamente tengamos el poder sobre 
la racionalidad sustantiva de los niños y niñas. El filósofo y psicoanalista francés Felix Guattari (2005) señaló:

... esquemáticamente hablando, diría que, así como se fabrica leche en forma de leche condensada con todas las moléculas que le son propias, se inyectan representaciones en las madres, en los niños, como parte del proceso de producción subjetiva. Muchos padres, madres, Edipos y triangulaciones son requeridos para recompensar una estructura restringida de familia. Se da una suerte de reciclaje $o$ de formación permanente para volver a ser mujer o madre, para volver a ser niño, o mejor, para pasar a ser niño, pues los adultos son infantiles. Los niños consiguen no ser infantiles por algún tiempo, en tanto no sucumben a esa producción de subjetividad.

La investigación participativa, se sustenta en lo anterior, es decir en el convencimiento que el juicio del niño(a) puede y debe ser reconocido en los procesos que generan conocimiento; resguardando su privacidad, dignidad, y siempre conservando su derecho a decidir sobre su suscripción en algún tipo de estudio.

Esta reflexión, sin embargo, no es nueva, basta registrar y tener presente algunos antecedentes históricos, como por ejemplo, los estudios desarrollados a fines de los años sesenta por dos sociólogos norteamericanos de la Universidad de Columbia. Rubin y Zavalloni (1969) realizaron una investigación sobre las aspiraciones de los jóvenes de Trinidad, los cuales fueron reconocidos como sujetos de investigación al incluir sus juicios y reflexiones integralmente, ya que en esos mensajes lingüísticos, el ser acontece y que en una de sus partes indicaba la expectativa de que ese examen fuera un paso adelante para llegar a ser tomados en cuenta.

Bajo este paradigma, al niño o niña se le facilita encauzar sus emociones a través del lenguaje, en el que Céspedes (2008) señala:

... el que adquiere a partir de esa edad el carácter de mediador y vehículo al servicio de la capacidad reflexiva. De modo gradual, el niño comienza a desarrollar una nueva habilidad: pensar acerca de lo que siente y ser capaz de verbalizarlo para su elaboración. (pág. 84) 
La propia UNICEF señala que "EI niño o niña necesita que se hable, que conversen con él y se le ayude a comunicar lo que piensa, lo que desea, lo que siente. Necesita que se le cuide, que se le responda a sus preguntas, dudas e inquietudes". Ello se refuerza, ya que el niño o niña de 3 años puede comenzar a formar frases, manejando aproximadamente 1.000 palabras y cuando inician su etapa escolar pueden alcanzar a usar hasta 6.000 palabras.

Según los expertos, a los 4 años aproximadamente, el niño o niña podría estar preparado para comprender ciertas preguntas y evocar mentalmente los hechos, sus actos y situaciones de la realidad que le rodea, pero también se dispone de los antecedentes que el niño o niña a los 2 o 3 años puede dibujar e interactuar mediante juguetes $u$ otras formas de estimulación manifestando su mundo interno y externo.

\section{Aspectos éticos y metodológicos de la investigación en infancia protagónica}

Considerando lo anterior, tenemos que en la edad preescolar o escolar, el niño o niña ya estaría con capacidad para dialogar y reconstruir su entorno desde su lenguaje. Esto quiere decir que, ya tiene la garantía de ser representado y significado por lo dicho y decible, por lo que el estudio debe someterse a su discurso. Esta situación determina que el investigador(a) re-conozca a la niña o niño como sujeto con habla propia y pleno de derechos. Además, desarrolla su experiencia social en la familia y su comunidad inmediata, desde donde penetra el mundo, provocando aprendizajes que se replican y vuelven a comprender y articular. Esta conducta en la vida cotidiana, que puede representarse desde diversas perspectivas, determina la construcción científica de la investigación.

Esta última afirmación, de carácter metodológico, engrana con la apreciación de Berger y Luckmann (1968), de que la realidad que comprende a la niña o niña in-situ. Expresan: "La vida cotidiana se presenta como una realidad interpretada por los hombres y que para ellos tiene un significado subjetivo de un mundo coherente" (p.36). Con ello se inicia un reconocimiento de tensiones y conflictos con diversas metodologías de investigación y con este marco se busca aportar experiencias significativas que contribuyan a reconocer a la niña o niño como sujeto pleno en materia de investigación. Este reconocimiento plantea la necesidad de establecer nuevos 
aspectos de forma y fondo para la producción de conocimiento. La niña o niño en el proceso dialógico de investigación desata reciprocidades constructivas con el investigador poniendo fin a ciertas lógicas externas de consistencia como las de Campbell y Stanley (1969).

Asumiendo la información anterior, la niña o niño se transforma en un sujeto calificado al cual se le debe salvaguardar su integridad. Con ello los investigadores no pueden dejar de preguntar a los niños si desean participar de un proceso de investigación, no pueden esconder o adulterar ciertos antecedentes. La invasión a la intimidad de la niña o niño debe ser protegida y/o regulada por comportamientos éticos de los investigadores con el propósito de resguardarles como personas y evitar su calificación como meros objetos de información.

Tal como lo señala Selltiz (1980), muchas veces, los procedimientos empleados para suscitar respuestas reveladoras se utilizan métodos invasivos o la manera en que escribe e informa sobre los resultados de un estudio pueden significar dilemas que podrían ocasionar graves implicancias, especialmente en niñas y niños vulnerables a las necesidades y deseos de conocimiento. El tiempo y la nueva perspectiva de Protección Integral de la Infancia, en el marco de los Derechos del Niño nos entregan las pautas para no violar la confianza de las niñas o niños y entrar en un trance y disputa de valores.

Otro aspecto metodológico es que, la estandarización metodológica en el área de la Infancia opera y se regula bajo protocolos de flexibilidad, colocando al trabajo científico en un dilema que tensiona la lógica y estructura operativa e instrumental de los estudios, de esta manera los criterios absolutos se flexibilizan y adecuan al contexto donde funciona la niña o niño.

\section{Avances en la percepción del niño o niña en los espacios institucionales}

Tal como se ha visualizado y establecido la importancia que adquiere la Doctrina de Protección Integral en el área de la investigación y formación de profesionales del Trabajo Social, así también, en el espacio profesional práctico. Si bien es cierto se trabaja con niños, niñas, adolescentes en casi todos los programas sociales en que participan los trabajadores sociales, en el campo especifico que ofrece Chile esta área de acción 
es el Servicio Nacional de Menores (Sename). Esta entidad es un organismo gubernamental ayudante del sistema judicial, dependiente del Ministerio de Justicia, creado por el Decreto Ley N 2.465 el 10 de enero de 1979, y su Ley Orgánica se publica en el Diario Oficial el 16 de enero del mismo año, entrando en vigencia el 1 de enero de 1980. El Sename, en la actualidad, tiene como objetivo la atención de la niñez y adolescencia vulnerada en sus derechos. Esto es, cuando su familia o sus cuidadores no le brinden los cuidados correspondientes porque cometan acciones u omisiones que afecten a niños (as) o por estar inhabilitados de hacerlo. También son atendidos por el Sename, jóvenes que se les imputan haber cometido un delito.

Este organismo del Estado tiene dos formas de ofrecer atención. Primero, es mediante centros directos, que atienden a la niñez vulnerada en sus derechos. Estos establecimientos coadyuvan a los tribunales diagnosticando las situaciones vivenciadas por los niños y además realizando reparación de estas vulneraciones. En lo referido a los jóvenes infractores, estos centros entregan la atención privativa de libertad que contempla la Ley de Responsabilidad Penal Adolescente (Ley 20.084). La segunda forma de atención, se refiere a la subvención de proyectos desarrollados por los organismos colaboradores acreditados, en el área de vulneración. Se trata de programas de prevención de las vulneraciones hasta residencias para niños, niñas y adolescentes separados de sus familias. En el área de infractores, son las sanciones del medio libre que establece la ley de Responsabilidad Adolescente. Referente al presupuesto con que cuenta el Sename, los centros directos gastan el $10 \%$ de este y los proyectos subvencionados gastan el $90 \%$, adjudicándose su ejecución mediante licitaciones públicas.

Respecto de la relación con los tribunales, el área de vulneración de derechos contempla la relación con los Tribunales de Familia desde el momento en que se diagnostican situaciones de alto nivel de complejidad hasta la derivación de esas vulneraciones para su atención en proyectos de tipo ambulatorio o residencial. Pero existe un nivel en que no se tiene relación con los Tribunales, y se encargan los proyectos de prevención y las Oficinas de Protección de Derechos (OPD). En el área de los jóvenes infractores existe una relación directa con los Tribunales de la Justicia Penal, a través de los jueces de garantía, los jueces del tribunal de juicio oral en lo penal, así 
como los fiscales adjuntos y los defensores penales públicos.

Desde la manera en que se entregan los recursos a los proyectos, se puede realizar una descripción de la gestión y desempeño de profesionales de Trabajo Social en este campo. En primer término, esta deducción se puede realizar a partir de la forma de entrega de atención, de profesionales de Trabajo Social. Estos (as) se insertan en el ámbito público y ejercen dos tipos de funciones: 1) las orientadas a indagación de las situaciones de vulneración que vivencian los niños, niñas y jóvenes, de manera de entregar todos los elementos que permitan la elección de parte del Juez de la mejor opción para el niño, niña o joven en su futuro, ya sea esto en el ámbito de la vulneración de derechos como en el ámbito de los jóvenes infractores; 2) la orientada al control de la ejecución de los proyectos sociales que reciben el financiamiento desde el Sename. Esta acción se constituye en velar porque la gestión de los proyectos y sus profesionales se lleve a cabo con la mirada de la Convención de los Derechos de los Niños y que con esto cumpla con lo comprometido para la recepción de subvención. De otro lado, los profesionales trabajadores sociales que se encuentran en el ámbito privado se desempeñan de acuerdo con las líneas de acción que Sename subvenciona, Oficina de Protección de Derechos (OPD), Diagnóstico, Residencias y Programas (Ley 20.032). Las gestiones son las siguientes:

1. Oficina de Protección de Derechos: esta es la puerta de entrada al sistema, donde se investiga la situación que vive el niño, llega derivado generalmente por la comunidad que detecta el problema, le informan a un equipo que consta de un psicólogo, un trabajador social y un abogado, este equipo debe indagar con el niño, la familia y la comunidad, cuál es hecho que vulnera al niño, para luego determinar de acuerdo a su nivel de gravedad dónde derivar. Por ejemplo, si se evalúa que lo que acontece es importante pero no afecta la integridad del niño o niña, se debe incorporar a los proyectos de la comuna o comunas circundantes, lo que se aborda en esta atención implican desde problemas simples como: maltrato leve, deserción escolar, primeras conductas de calle, faltas o negligencia leve; hasta situaciones mayores como: maltrato grave, abuso sexual, abandono y es aquí donde conocen e intervienen los Tribunales 
de Familia.

2. Diagnóstico: frente al maltrato grave, abuso sexual, violación, abandono o cualquier vulneración grave, al Juez de Familia le interesa conocer qué le sucedió al niño, por lo que el trabajador o trabajadora social opera en forma conjunta con un psicólogo, donde investiga qué le pasó al niño, para después demostrar la culpabilidad del adulto imputado del delito sobre el niño. Este es un proceso que interviene desde el dolor del niño por el ataque vivido, que si bien se trata de evitar que se repita la explicación de lo que vivió con muchas personas, aun el sistema judicial no ha logrado eliminar este factor de revictimización del niño. El objetivo final es que el Proyecto de Diagnóstico derive su situación a otro Proyecto que trate su problema y solucione su situación familiar.

3. Residencias: Este tipo de proyectos es para niños o niñas muy vulnerados, donde la familia no cuenta con redes para acoger al niño. La tarea del profesional de Trabajo Social es desarrollar y habilitar estas redes, situaciones complejas porque el dolor familiar está abierto y se debe recomponer lazos y miradas, en conjunto con el psicólogo. Es un desafío que cuesta asumir profesionalmente. $\mathrm{Y}$ generalmente, estos proyectos requieren de apoyo desde programas externos para apoyar su reparación, ya que estos niños traen secuelas psicológicas que afectan su actuar cotidiano, el maltrato produce niños violentos, la negligencia empuja a la calle, y por tanto los niños son autosuficiente y sin normas, entre otras conductas que produce estas vulneraciones. Esto hace que el trabajador social de la residencia deba también preocuparse de normalizar conductas, junto con abrirle posibilidades a una reinserción social y familiar que aporte a su desarrollo evolutivo y psicológico apropiado.

4. Programas: Finalmente en este tipo de atención ambulatoria se encuentran proyectos que van desde lo más simple como la prevención en comunidad, donde el objetivo es efectuar acciones socioeducativas con los niños para lograr su empoderamiento acerca de los 
derechos de los niños; hasta programas de reparación del maltrato, donde los familiares o adultos responsables del niño los llevan a atención para resignificar la situación traumática vivida y para aprender a vivir con situaciones como la falta del padre que cometió un delito hacia él y el otro padre que avaló la situación. Escenarios por demás difícil de incorporar por parte de los niños. Por otra parte, estos Programas son múltiples. Existen los programas de intervención breve, los programas de intervención especializadas, otros más específicos los que atienden a niños, niñas y adolescentes expuestos a la explotación sexual; tanto es así que en este ámbito se incluyen los Programas de Sanciones del Medio Libre que son parte de la Ley de Responsabilidad Penal Adolescente (Ley 20.084).

Frente a estos tipos de atención se puede decir que las técnicas que desarrollan con mayor frecuencia, profesionales de Trabajo Social son:

La entrevista en profundidad, aplicando ecomapas y genogramas. Esta entrevista se utiliza para que el profesional en las Oficinas de Protección de Derechos y el Diagnóstico emitan una opinión ante el Tribunal de Familia, respecto a lo que le va acontecer a él, y ante el Tribunal Penal, para defender su informe pericial, a fin de que el abogado del imputado dé su opinión de los hechos, y se dicten las penas correspondientes.

En residencias se aplica la entrevista como apoyo a la intervención, donde se interviene desde la mirada del interés superior del niño, elaborando la situación que lo afecta, apoyándolo en su proceso de superación de la vulneración, en lo familiar como en lo psicológico, por lo cual la acción es conjunta con el profesional psicólogo es importante para determinar los pasos a seguir. Sin embargo, existe una técnica que usa de manera muy esbozada, que es la observación participante, siendo muy productiva, debido a que permite analizar las conductas del niño en su contexto habitual, desde donde se obtiene una visión más certera de lo que vivencia, porque manifiesta todos sus síntomas, para que luego estos puedan ser tratados a nivel individual $y$ familiar. 
En los casos de los programas, profesionales del Trabajo Social tienen como finalidad principal reconstituir las redes familiares, por lo cual aquí se les consulta a los adultos y se les guían para que puedan cubrir adecuadamente las necesidades de los niños, trabajando en dupla con el psicólogo. En lo referido a los Programas de Prevención Comunitaria, la finalidad es la guía y orientación del trabajo de grupo para el empoderamiento de los derechos de los niños, labor que ha sido compartido con el psicólogo social, en este nivel de acción en algunas ocasiones se realizan grupos de discusión para obtener opiniones respecto a analizar percepciones 0 ideas que se desean incorporar en la reflexión de los niños y jóvenes. Para el caso de los Proyectos que aplican las sanciones de la Ley de Responsabilidad Penal Adolescente, se utiliza la conversación como forma de seguimiento y acompañamiento a los jóvenes en la reinserción social, siendo esta una construcción de realidades donde se pretende que los jóvenes cambien valores y se responsabilicen de sus acciones.

La gestión de los trabajadores y trabajadoras sociales en general está marcada por la Doctrina de Protección Integral, mirada que se integra tanto desde el pregrado como desde la visión que se tiene como Estado en términos de qué se les pide como profesionales que atienden en este ámbito de acción. Respecto de la vulneración de derechos graves como maltrato, abuso, explotación laboral, explotación sexual, conductas de calle y otras vulneraciones como país, se ha ido avanzando notablemente, tanto en legislación como en la mirada como sociedad, existe una sanción social importante al respecto. Sin embargo, un aspecto que aún no ha evolucionado es lo relativo a la estigmatización, tratamiento y preocupación en lo referido a los jóvenes infractores. Las leyes aún no contemplan una adecuada reinserción. La sociedad en su conjunto no ha desarrollado todas las estrategias que permitan su reconocimiento y trabajo en la recuperación de estos jóvenes. Al contrario, nuestra sociedad extremadamente individualista, consumista y estereotipada no los reconoce como resultado de ella y aún no se hace responsable de ellos. Es necesario hacer un análisis en mayor profundidad de la gestión general de los 
programas de aplicación de medidas y sanciones para estos jóvenes, analizando tanto el quehacer profesional, como lo intersectorial, ya que se necesita la participación de todos para no solamente aplicar sanciones, sino poner un mayor esfuerzo en la reinserción de los jóvenes.

\section{Conclusiones}

Hoy en día, en estudios de pregrado del Trabajo Social, se movilizan una pluralidad de métodos de investigación acción, pero también se apela a perspectivas cualitativas e interaccionistas simbólicas en pos de capturar información relevante para la acción profesional. Las perspectivas cualitativas, por ejemplo, permiten acceder desde un enfoque singular a los contextos cotidianos que les rodea rescatando activamente el punto de vista de los niños y niñas.

Ejemplos de la utilización de estos criterios en la Escuela de Trabajo Social de la Universidad Tecnológica Metropolitana y que respaldan la reflexión sostenida son las diversas investigaciones de pregrado. En todos estos estudios se accede al niño o niña de manera integral, legitimando su participación como interlocutor válido en la generación de conocimientos. Este respeto a la niñez es una base que dignifica al investigador(a) de la infancia sobre todo si observamos la manera que desde el pregrado esta visión de niño-actor se proyecta en el ejercicio práctico en el Trabajo Social chileno que se realiza con la infancia vulnerada en sus derechos de cuidado parental, tales como, maltrato, abuso, negligencia, abandono y expulsión familiar, las técnicas dependen desde la atención que se les esté otorgando.

En el espacio profesional, aún el trabajador o trabajadora social no ha valorado estos espacios de intervención como posibles para de realizar estudios cualitativos, que arrojen las opiniones de los niños, niñas y adolescentes acerca de la atención que están recibiendo, para luego contrastarlos con las sistematizaciones que se deben entregar para la continuidad de los proyectos. Estos estudios permitirían mejorar los modelos metodológicos y adecuarlos a las necesidades y los contextos de los niños y niñas, siendo relevantes porque los niveles centrales del Estado no pueden acceder a ellos(as) y los profesionales tienen la responsabilidad de visibilizarlos. Esto sólo se puede tener si se llevan a cabo investigaciones desde su acción profesional. Sería una forma de mostrar a los niños y 
niñas, los análisis que se pueden efectuar de su realidad social que, generalmente es bastante diferente de lo que se percibe idealmente en los organismos del Estado. 


\section{Referencias}

Alarcón A, Erick, \& Fuentes, Caroline. (2004). Niños, niñas y adolescentes de la calle, un estudio exploratorio acerca de la realidad que enfrentan. Tesis no publicada, Universidad Tecnológica Metropolitana, Santiago de Chile.

Barlow, David, \& Hersen, Michel. (1988). Single case experimental design: Strategies for studying behavior change. Martínez Roca (Trad.). New York: Pergamon Press.

Beloff, Mary. (1999). Modelo de la Protección Integral de los Derechos del Niño y de la Situación Irregular: un modelo para armar y otro para desarmar. Revista Justicia y Derechos del Niño, 1, 37-48. (Unicef).

Berger, Peter, \& Luckmann, Thomas. (1968). La construcción social de la realidad. Buenos Aires, Argentina: Editorial Amorrortu.

Campbell, Donald, \& Stanley, Julian. (1978). Diseños experimentales y cuasiexperimentales en la investigación social. Buenos Aires, Argentina: Editorial Amorrortu.

Carreño B. Paula, \& Castro F. Daniela. (2005). La discriminación socio-comunitaria de niñas y niños entre 8 y 12 años, que viven en campamentos urbanos de la región metropolitana, pertenecientes a la Fundación un Techo para Chile. Tesis no publicada, Universidad Tecnológica Metropolitana, Santiago de Chile.

Céspedes, Amanda. (2008). Educar las emociones. Santiago de Chile: Ediciones B Chile, S.A.

Erickson, Erik. (2000). Ciclo vital completado. España: Editorial Paidós.

Espínola B. Pamela, Trujillo C. Carolina, \& Valenzuela G. Cindy. (2006). Ruptura del subsistema matrimonial: ¿Cuánto le cuesta a los hijos? Tesis no publicada, Universidad Tecnológica Metropolitana, Santiago de Chile.

Espinoza G. Eduardo. (2010). Género y resiliencia: Una mirada a las estrategias que hombres y mujeres han utilizado para la superación de la adversidad y/o situaciones de vulneración. Tesis no publicada, Universidad Tecnológica Metropolitana, Santiago de Chile.

Facuse S. Jeannette, \& Ramírez P. Elizabeth. (2008). Niños y adolescentes menores de 15 años que han ingresado al Tribunal de Familia de Puente Alto por algún conflicto con la ley penal y su relación con la exclusión social. Tesis no publicada, Universidad Tecnológica Metropolitana, Santiago de Chile.

García Méndez, Emilio. (1994). Derecho de la Infancia/Adolescencia en América Latina: De la Situación Irregular a la Protección Integral. Santa Fé de Bogotá, Colombia: Forum Pacis. 
Guattari, Felix, \& Rolnik, Suely. (2005). Micropolítica. Cartografías del deseo. Madrid, España: Editora Vozes Itda.

Matus, Teresa. (1999). Propuestas contemporáneas en Trabajo Social. Hacia una intervención polifónica. Buenos Aires, Argentina: Espacio Editorial.

ONU. (1989). Convención de los Derechos del Niños, Naciones Unidas. Adoptada y abierta a la firma y ratificación por la Asamblea General en su resolución 44/25. New York: Autor

Piaget, Jean. (2000). El nacimiento de la inteligencia en el Niño. Barcelona, España: Editorial Crítica.

Rubin, Vera, \& Zavalloni, Marisa. (1969). We wish to be looked upon, Teacher. New York: College Press, Teacher College.

Saavedra Natalie, \& Rojas M. Lehya. (2009). Representaciones sociales de niños y niñas, menores de 14 años que vivencian situaciones de alta complejidad, para la construcción de un perfil familiar y social. Tesis no publicada, Universidad Tecnológica Metropolitana, Santiago de Chile.

UNICEF. (2004). Desarrollo psicosocial de los niños y las niñas. Colombia: Autor. 